\title{
CENPRE 30 anos
}

O CENTRO DE ESTUDOS, PREVENÇÃO E RECUPERAÇÃO DE DEPENDENTES QUÍMICOS, CENPRE - FURG é um Grupo organizado para acolher pessoas, visando prevenir e tratar transtornos relacionados ao uso de substâncias químicas. Destina-se também a formação de recursos humanos, a prevenção e a pesquisa. Vem ajudando as pessoas a resgatar uma vida de qualidade, construindo, juntos, novos caminhos, constituindo-se, assim, em suporte e apoio para a saúde da comunidade.

O Grupo nasceu nos idos dos anos 80. Aproveitou a característica da FURG de interação com a comunidade e em 1989, no antigo Departamento de Ciências Fisiológicas (hoje Instituto de Ciências Biológicas) deu início ao trabalho extensionista com o Projeto Educativo e Preventivo sobre Drogas Psicotrópicas ou PROJETO DROGAS como ficou conhecido, com as ações centradas principalmente na prevenção.

Coordenou o primeiro projeto institucional na área de prevenção às drogas psicoativas com o objetivo de conhecer a realidade sobre o consumo de drogas nas escolas dos municípios do Rio Grande, Santa Vitória do Palmar e São José do Norte, RS. Apresentou os resultados deste levantamento para as escolas e iniciou uma discussão sobre a implantação de um programa de capacitação para formar multiplicadores com o intuito de mantê-los informados, atualizados na temática e poder enfrentar os desafios nas escolas e nos locais de trabalho.

Voltou-se também para a própria instituição e propôs um programa interno educativo e preventivo sobre o consumo de drogas psicotrópicas, traçando o perfil dos servidores e adotando medidas de prevenção.

As ações do CENPRE se desenvolveram no cenário marcado pela reforma psiquiátrica, a promulgação da Constituição de 1988 e da lei orgânica da saúde. O Ministério da Saúde lançava um conjunto de proposições para enfrentar as questões relativas aos usuários de drogas com ações nas áreas de prevenção e tratamento.

Nesta mesma época iniciava-se, organizado pelo Centro de Informações sobre Drogas (CEBRID) uma série de levantamentos nacionais sobre o consumo de drogas psicotrópicas entre estudantes do ensino fundamental e médio das redes pública e privada de ensino com o intuito de conhecer a prevalência e os padrões de consumo de drogas e suas consequências sobre os estudantes brasileiros de ensino fundamental e médio.

Estados-membros da ONU decidiram fortalecer as ações para combater o tráfico de drogas A Convenção de 1988 teve como objetivo promover a cooperação entre os Estados para tratar de forma mais eficaz o tráfico de drogas, acabar com os lucros de organizações criminosas através da produção de drogas ilícitas e do tráfico e fornecer novas ferramentas aos governos. A Convenção também buscou reduzir o sofrimento humano e pediu que os Estados adotassem medidas efetivas nas áreas de prevenção, tratamento e reabilitação. 
Adequando-se as políticas públicas e considerando-se, na época, a carência de serviços especializados na região, o Grupo começou a atuar também na área de recuperação de dependentes químicos. Então nasceu o CENPRE. A base do Centro foi o Grupo do Projeto Drogasque há quase dez anos trabalhava na comunidade. Servidores da Superintendência de Administração de Recursos Humanos da FURG foram incorporados com outros voluntários vindos da comunidade. Em 21 de agosto de 1999 o CENPRE deu início ao seu Serviço de Tratamento e à organização do Serviço de Banco de Dados, mantendo ativo o Serviço de Prevenção já existente.

Em 2010 o CENPRE tornou-se um dos 49 Centros Regionais de Referência (CRR/SENAD) para Formação Permanente dos profissionais que atuam nas redes de atenção integral à saúde e de assistência social com usuários de crack e outras drogas e seus familiares. Habilitou-se para dar início a uma série de cursos de capacitação para os profissionais que atuam na rede de saúde da $3^{\mathrm{a}}$ e $7^{\text {a }}$ Coordenadoria Regional de Saúde do RS.

O CENPRE está localizado no Hospital Universitário FURG/EBSERH. Nos últimos anos empreendeu as seguintes ações:

- Atendimentos ambulatoriais de caráter individual a pessoas com problemas relacionados ao uso de substâncias psicoativas, por uma equipe multidisciplinar (psicólogo, assistente social, enfermeiro, consultor terapêutico, médico psiquiatra).

- Atendimentos em grupos terapêuticos para pacientes com alta ambulatorial ou sintomas em remissão, pacientes em tratamento e familiares.

- Atividades de formação com o curso de Abordagem Multidisciplinar em Dependência Química, estando em sua oitava turma de formação (2019), prática de estágios curriculares dos acadêmicos de cursos da área da saúde (psicologia, enfermagem e medicina), cursos de capacitação profissional e de extensão universitária.

- Ações de prevenção voltadas a escolares em situação de vulnerabilidade social e demais setores da sociedade.

- Ações de pesquisa com o desenvolvimento de projetos relacionados tema do uso e abuso de substâncias psicoativas com a finalidade de subsidiar cientificamente as intervenções, assim como, contribuir de maneira efetiva na produção de conhecimentos relacionados ao tema.

Com as suas atividades vem ajudando as pessoas a resgatar uma vida de qualidade, construindo, juntos, novos caminhos, constituindo-se, assim, em suporte e apoio para a saúde da comunidade.

Ana Luiza Muccillo Baisch

Coordenadora do CENPRE 